\title{
Effect of Soil Moisture on the Angular Variation of Thermal Infrared Emissivity of Inorganic Soils
}

\author{
Vicente García-Santos, Enric Valor, Vicente Caselles, Mª Ángeles Burgos and César Coll
}

\begin{abstract}
Accurate knowledge of thermal infrared emissivity is required to retrieve accurate values of surface temperature. Emissivity is influenced by different factors, so the present study deals with the effect of the soil moisture (SM) content on the zenithal $(\theta)$ variation of ratio-to-nadir emissivity $(\varepsilon r)$, for a wide variety of inorganic bare soils. To retrieve $\varepsilon_{r}$ a goniometer assembly was used, together with two identical CIMEL CE312-2 radiometers working at six spectral bands within $7.7-14.3 \mu \mathrm{m}$, performing simultaneous radiance measurements at different combinations of zenith and azimuth angles. Results showed that the effect of $S M$ upon $\varepsilon_{r}(\theta)$ is different depending on the spectral range and textural composition of the sample. Sandy soils showed a decrease of $\varepsilon_{\mathrm{r}}(\theta)$ from nadir of 0.132 for $\theta \geq 40^{\circ}$ at $8-9.4 \mu \mathrm{m}$ under dry conditions, but this decrease was reduced to 0.093 with the increase of SM. Clayey samples did not present dependence on $\varepsilon_{r}(\theta)$ with $S M$. Loamy texture samples presented a more sharply decrease of $\operatorname{\varepsilon r}(\theta)$ with the increase of $\mathrm{SM}$, reaching difference between nadir values and $70^{\circ}$ up to $6 \%$, at all spectral ranges studied. Finally, a parameterization of $\varepsilon_{r}$ with SM and $\theta$ was derived allowing to obtain ratio-to-nadir emissivities with an accuracy of $\pm \mathbf{0 . 0 1 1}$.
\end{abstract}

Index Terms-Angular emissivity, bare soil, remote sensing, soil moisture, thermal infrared.

\section{INTRODUCTION}

EMISSIVITY $(\varepsilon)$ is a characteristic property of natural land surfaces that is coupled with land surface temperature (LST) in a radiance measurement in the thermal infrared (TIR) spectral domain. LST plays a key role in numerous geophysical processes like retrieving accurate long-wave surface energy fluxes in the atmosphere-surface interface [1], for instance. For this reason, a good knowledge of surface thermal emissivity and its influencing physical variables are needed. Factors such as soil composition and texture [2], soil moisture (SM) [3-4] or viewing geometry [5-6] must be taken into account when analyzing satellite TIR data, since their influence on $\varepsilon$ is significant.

Recently, the effects of SM and viewing geometry on thermal $\varepsilon$ for a wide variety of inorganic bare soils (IBS) with different texture, have been analyzed separately ([3], [4] and [6]). Regarding SM, it was observed in general an increase of $\varepsilon$ with SM that was more notable for sandy soils, and in the 8$9 \mu \mathrm{m}$ spectral range [3-4]. In relation to the angular variation of $\varepsilon$, results from [6] showed that $\varepsilon$ of dry IBS is almost azimuthally isotropic, and decreases in the zenithal direction beyond $40^{\circ}$, with the maximum variation observed on sandy soils rich in quartz and within 8-9.4 $\mu \mathrm{m}$.
The main objective of the present paper is to study the effect produced by SM on the anisotropy of thermal $\varepsilon$, extending the results obtained in the study carried out in a previous work [6], by combining the effect of SM and viewing angle for the same samples. In section II, IBS samples and instrumentation are presented together with the methodology followed to measure the radiance at different angles, and SM measurements. Section III shows the retrievals of ratio-tonadir band emissivity $\left(\varepsilon_{\mathrm{r}}\right)$ for different viewing angles and SM values at each IBS. Results obtained are discussed. Section IV used results obtained to retrieve a regression of the ratio-tonadir emissivity for any IBS as a function of SM and $\theta$. Finally, conclusions are presented in section IV.

\section{EXPERIMENTAL SETUP}

Twelve IBS samples were chosen to evaluate the variation of TIR $\varepsilon_{\mathrm{r}}$ with SM and viewing angles according to different soil texture. Table I lists the textural and mineralogical features for the IBS selected to carry out the study.

TABLE I

ORGANIC MATTER (OM) CONTENT, AND TEXTURAL AND MINERALOGICAL FEATURES OF THE ELEVEN IBS SELECTED FOR THE ANALYSIS.

\begin{tabular}{|c|c|c|c|c|c|c|c|c|c|c|c|}
\hline \multirow{2}{*}{ Soil } & \multirow{2}{*}{ OM } & \multicolumn{3}{|c|}{ Textural classification } & \multicolumn{6}{|c|}{ (\%) } & \multicolumn{7}{|c|}{ coderal classification (\%) } \\
\cline { 3 - 11 } & (\%) & S & L & C & Q & F & Fi & H & Ca & Gi & G \\
\hline B & 0.1 & 99 & 0.9 & 0.1 & 95.3 & 2.9 & - & - & - & - & - \\
BR3 & 1.69 & 92 & 2 & 6 & 100 & - & - & - & - & - & - \\
WS & 0.21 & 100 & 0 & 0 & 1 & - & - & - & - & - & 99 \\
LW03 & 0.73 & 77 & 18 & 5 & 53.7 & 46.3 & - & - & - & - & - \\
BR2 & 1.47 & 69 & 15 & 16 & 82.3 & 16.8 & 0.8 & - & - & - & - \\
LW52 & 1.71 & 62 & 15 & 23 & 58.4 & 32.2 & 9.4 & - & - & - & - \\
LW13 & 1.61 & 51 & 35 & 14 & 76 & 16.7 & 4.8 & 2.6 & - & - & - \\
F & 3.5 & 50 & 30 & 20 & 19.9 & 4.5 & 4.1 & 8.7 & 62.9 & - & - \\
BR1 & 2.93 & 40 & 6 & 54 & 37.9 & - & - & 13.1 & - & 49 & - \\
LW45 & 1.15 & 29 & 54 & 17 & 72.4 & 23.4 & 4.2 & - & - & - & - \\
C & 8.9 & 20 & 43 & 37 & 29.4 & 5.5 & 9 & - & 56.1 & - & - \\
D & 4.5 & 14 & 50 & 35 & 19.3 & 3.5 & 6 & 8.9 & 62.3 & - & - \\
\hline
\end{tabular}

Textural parameters $\mathrm{S}, \mathrm{L}$ and $\mathrm{C}$ are percentages of sand, silt and clay, respectively.Mineralogical parameters Q, F, Fi, H, Ca, Gi and G are respectively percentages of quartz, feldspar, filosilicates, hematite, calcite, gibbsite and gypsum.Additional details about these IBS can be found in [3] and [4].

Radiances were taken with a multispectral thermal radiometers CIMEL Electronique model CE312-2 [7], working in six different spectral bands: 7.7-14.3 $\mu \mathrm{m}$ (channel 1), 8.2-8.7 $\mu \mathrm{m}$ (channel 6), 8.4-8.9 $\mu \mathrm{m}$ (channel 5), 8.9-9.4 $\mu \mathrm{m}$ (channel 4), 10.1-11.1 $\mu \mathrm{m}$ (channel 3) and 10.9-11.9 $\mu \mathrm{m}$ 
(channel 2). with an uncertainty temperature of: $\pm 0.03 \mathrm{~K}, \pm$ $0.02 \mathrm{~K}, \pm 0.03 \mathrm{~K}, \pm 0.018 \mathrm{~K}, \pm 0.03 \mathrm{~K}$ and $\pm 0.02 \mathrm{~K}$, channels 1 to 6 respectively, obtained after comparison with temperatures from a reference blackbody whose values presented a maximum bias of $-0.19 \mathrm{~K}$ with regard to a reference transfer radiometer [8]. Ratio-to-nadir was retrieved taking two simultaneous radiance measurements, one at nadir and another at an arbitrary angular configuration $(\theta, \varphi)$, by means of equation:

$$
\varepsilon_{r i}(\theta, \varphi)=\frac{\varepsilon_{i}(\theta, \varphi)}{\varepsilon_{i}(0,0)}=\frac{L_{i}(\theta, \varphi)-L_{i}^{\downarrow}}{L_{i}(0,0)-L_{i}^{\downarrow}}
$$

where $\mathrm{L}_{\mathrm{i}}{ }^{\downarrow}$ is the spectral hemispherical downwelling radiance, measured by means of a gold diffuse reflectance panel ([6], [9]), which was placed inside the FOV of CE1 at $0^{\circ}$. The time interval between two consecutive panel measurements was less than 18 minutes. Given that Eq. (1) is the quotient between absolute emissivity from an angular configuration and nadir, a previous knowledge of absolute emissivity at nadir [4] allows estimation of the absolute value of emissivity in that specific angular configuration.

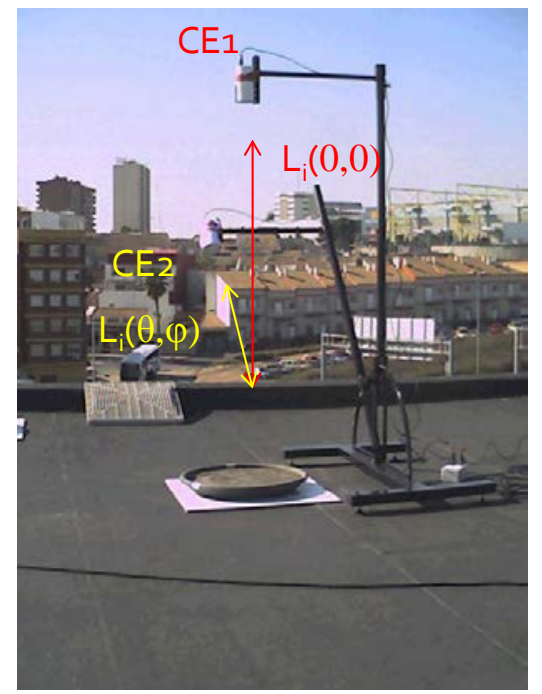

Figure1. Experimental ensemble used in the study for two simultaneous measurements at nadir (CE1) and at viewing direction $(\theta, \varphi)($ CE2).

To retrieve $\varepsilon_{\mathrm{r}}$ values, radiance measurements over the sample were taken simultaneously using a goniometer in which the two CE312-2 radiometers were placed (see Figure 1 ), one at nadir (CE1), and the second one in a specific direction $(\theta, \varphi)(\mathrm{CE} 2)$. The latter radiometer could be moved along the arm of the goniometer varying the field of view over the sample, in order to measure the same area as the nadir radiometer. Radiance measurements were taken at different combinations of zenith and azimuth angles. Zenith angles were considered from $\theta=10^{\circ}$ to $\theta=70^{\circ}$ at intervals of $10^{\circ}$. For each zenith angle, the IBS emissivity was measured at three different azimuthal orientations turning the samples $120^{\circ}$ each time, instead of turning the goniometer-radiometer system. Azimuthal rotation was repeated two more times for each zenith angle.

Each IBS samples was placed in a circular container $52 \mathrm{~cm}$ in diameter and $10 \mathrm{~cm}$ height (Fig.1) which had multiple holes in its bottom, designed for allowing the water drainage. Moreover, a sieve was attached to the bottom (between holes and sample) to avoid the loss of the finest particles. Samples were flooded allowing filtration through the container and straightaway freely air dried.

Radiance measurement process started with a completely dry sample and they were performed at several times during the drying process, after saturation, so the ratio-to-nadir band emissivity could be measured at different SM levels. If soil cracks appeared during the drying process, they were removed when possible. The whole set of angular radiance measurements, for a given sample at a specific SM level, lasted $50 \mathrm{~min}$. The sequence of soil saturation and drying was repeated one more time in order to check the validity and reproducibility of the results.

Volumetric SM content from moist IBS samples, was retrieved with a Delta-T SM200 sensor which has a calibration uncertainty of $\pm 0.03 \mathrm{~m}^{3} \cdot \mathrm{m}^{-3}$ according to the manufacturer. SM was measured puncturing the rods $(5 \mathrm{~cm}$ long) of the SM200, at different points of the IBS surface. SM measurements were taken before and after each set of radiance measurements, in order to check possible spatial and temporal variations of SM in the sample. Standard deviation of all these $\mathrm{SM}$ measurements was always lower than $\pm 0.03 \mathrm{~m}^{3} \cdot \mathrm{m}^{-3}$, assuring moisture homogeneity in the soil during the measurement process.

\section{RESULTS AND DISCUSSIONS}

The uncertainty in the ratio-to-nadir band emissivity, $\delta \varepsilon_{\mathrm{ri}}(\mathrm{SM}, \theta, \varphi)$, associated to a specific angular direction $(\theta, \varphi)$ was chosen at the maximum of three values: (i) Average of the three values obtained for a single $(\theta, \varphi)$ configuration, which were calculated by applying error propagation to Eq. (1) with radiance uncertainties given by the radiometer calibration errors. (ii) Standard deviation of these three $\varepsilon_{\text {ri }}$ values. (iii) Difference between maximum and minimum values of $\varepsilon_{\mathrm{ri}}$ at specific $(\theta, \varphi)$, divided by four. Results showed that $97 \%$ of $\delta \varepsilon_{\mathrm{ri}}(\mathrm{SM}, \theta, \varphi)$ ranged from \pm 0.001 to \pm 0.010 . The azimuthal dependence of $\varepsilon_{\mathrm{ri}}$ in all cases was less than the maximum emissivity error $( \pm 0.010)$ as was the case in the previous work [6], concluding that $\varepsilon_{\text {ri }}$ of an IBS can be retrieved, regardless the $\varphi$ angle, with a maximum uncertainty of \pm 0.010 , for a specific $\theta$ and SM content. The emissivity variation was more significant in terms of zenith angle and SM content. Figure 2 show the ratio-to-nadir emissivity variation with SM for different zenith angles, at channels 1 (7.7-14.3 $\mu \mathrm{m}), 3$ (10.1$11.1 \mu \mathrm{m})$ and $5(8.4-8.9 \mu \mathrm{m})$ of CE312-2, and for the samples: B (representative of sandy samples BR3, WS and LW03), F (representative of loamy textures samples BR2, LW13, D and C), BR1 and LW45 (as unique clayey and sitly samples, respectively), to summarize the observed behavior in all samples (the complete set of measurements can be obtained from the authors upon request). Conclusions driven from channel 3 data can be extended to channel 2 (10.9-11.9 $\mu \mathrm{m})$, and from band 5 to channels $4(8.9-9.4 \mu \mathrm{m})$ and $6(8.2-8.7$ $\mu \mathrm{m})$. 

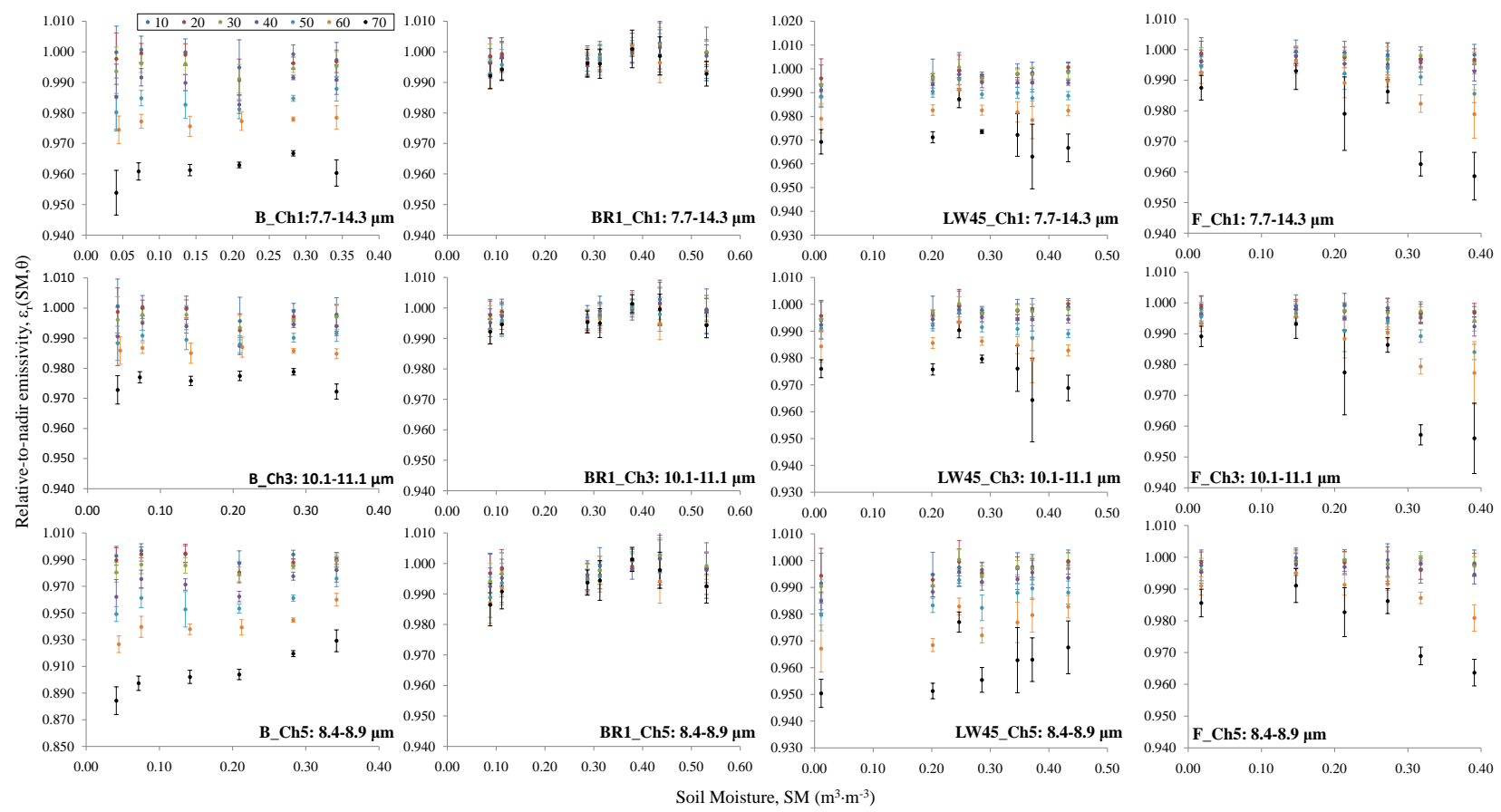

Figure 2. Angular variation of $\varepsilon_{\mathrm{r}}(\theta)$, for $\theta=10^{\circ}-70^{\circ}$ at $10^{\circ}$ intervals, for soil samples $B, B R 1, L W 45$ and $F$, as function of SM content for spectral channels 1,3 and 5 of CE312-2. Uncertainty associated to $\varepsilon_{r}(\theta)$ is the standard deviation of 9 measurements $(3$ repetitions at a specific $(\theta, \varphi)$ configuration $x 3$ different $\varphi$ angles). Label of top left-corner graph can be applied to the rest.

Results show that angular effect of SM on $\varepsilon_{\mathrm{ri}}(\theta)$ exhibits different behavior as a function of the spectral range and textural composition of the sample. Sandy soils show significant decreases of $\varepsilon_{\mathrm{ri}}(\mathrm{SM}, \theta)$ at $8-9.4 \mu \mathrm{m}$ for $\theta \geq 30^{\circ}$, independently on SM. Under dry conditions, $\varepsilon_{\mathrm{ri}}(\mathrm{SM}, \theta)$ presents maximum decreases for sandy soils from nadir ranging between 0.021 (at $\theta=30^{\circ}$ ) to 0.132 (at $\theta=70^{\circ}$ ), for sample $B$ at $S M=0.04 \mathrm{~m}^{3} \cdot \mathrm{m}^{-3} \cdot \varepsilon_{\mathrm{ri}}(\mathrm{SM}, \theta)$ of sandy soils decrease from nadir in a less notable way under wet conditions, but it is still significant for $\theta \geq 30^{\circ}$, ranging between 0.019 (at $\theta=30^{\circ}$ ) to 0.093 (at $\theta=70^{\circ}$ ), for sample $\mathrm{B}$ at $\mathrm{SM}=0.28 \mathrm{~m}^{3} \cdot \mathrm{m}^{-3}$. It is possible that increasing soil water content results in a decrease of the spectral contrast of emissivity, because water is strongly absorbing in the region of the quartz reststrahlen bands [2], thus reducing the effect of quartz. Sample WS presents abundant content of gypsum (99\%), which has a weak absorption in the spectral region 8-9 $\mu \mathrm{m}$ [10], so it is expected that water content acts with gypsum similarly than with quartz at the reststrahlen bands. The decrease of $\varepsilon_{\text {ri }}$ with $\theta$ remains constant at spectral range 10-12 $\mu \mathrm{m}$, regardless of water content in the soil, being significant only for $\theta \geq 60^{\circ}$. As shown by [6], this decrease has an average value of 0.012 at $\theta=60^{\circ}$, and 0.019 at $\theta=70^{\circ}$. Finally, $\varepsilon_{\text {ri }}$ of sandy soils (B, WS, BR3 and LW03) at broad spectral range 7.7-14.3 $\mu \mathrm{m}$ also shows constant decrease with $\theta$ independently on SM, but at this spectral range $\varepsilon_{\text {ri }}$ decreases significantly for $\theta \geq 50^{\circ}$, with an average decrease of 0.012 for $\theta=50^{\circ}, 0.019\left(\theta=60^{\circ}\right)$ and $0.029\left(\theta=70^{\circ}\right)$.

Clayey IBS BR1 shows a decrease of $\varepsilon_{\mathrm{r}}$ with $\theta$ nearly independent on both SM and the spectral ranges studied, being significant for $\theta \geq 50^{\circ}$, with a maximum decrease of $\varepsilon_{\mathrm{r}}$ (under dry conditions) of 0.013 for $\theta=50^{\circ}, 0.014\left(\theta=60^{\circ}\right)$ and 0.016 $\left(\theta=70^{\circ}\right)$.
Soil LW45 shows a similar behavior on $\varepsilon_{\mathrm{ri}}(\mathrm{SM}, \theta)$ as sandy soils, probably because the presence of high quartz content in its sand percentage. At 8-9.4 $\mu \mathrm{m}$ and under dry conditions, significant decrease of $\varepsilon_{\mathrm{ri}}(\mathrm{SM}, \theta)$ from nadir, begins at $\theta=40^{\circ}$ ranging from $0.011\left(\theta=40^{\circ}\right)$ to $0.059\left(\theta=70^{\circ}\right)$. For high $\mathrm{SM}$ values, decrease of $\varepsilon_{\mathrm{ri}}(\mathrm{SM}, \theta)$ from nadir is significant for $\theta \geq$ $50^{\circ}$, ranging between $0.011\left(\theta=50^{\circ}\right)$ and $0.036\left(\theta=70^{\circ}\right)$. At spectral ranges $10-12 \mu \mathrm{m}$ and 7.7-14.3 $\mu \mathrm{m}$, decrease of $\varepsilon_{\mathrm{ri}}$ from nadir is independent on SM content, reaching significant differences of 0.014 and 0.017 (at $\theta=60^{\circ}$ ) and 0.023 and 0.028 (at $\theta=70^{\circ}$ ), respectively.

For the rest IBS samples with loamy textures (BR2, LW13, F, D and C), the observed behavior is opposite to that of sandy soils, $\varepsilon_{\text {ri }}$ decreases with $\theta$ more sharply with the increase of water content. In [6] showed that emissivity decrease of these soils, when they are completely dry, is moderate (less than 3\% at $\theta=70^{\circ}$ ) at all six spectral ranges studied. Our results agreed with those of [6] under dry conditions, but the decrease of $\varepsilon_{\mathrm{ri}}$ with $\theta$ is more notable with the increase of SM, being significant at all spectral ranges for $\theta \geq 50^{\circ}$. $\varepsilon_{\mathrm{ri}}$ has an average decrease respect to nadir of $0.013\left(\theta=50^{\circ}\right), 0.020\left(\theta=60^{\circ}\right)$ and $0.035\left(\theta=70^{\circ}\right)$, at all spectral ranges studied when IBS is saturated.

It is known that emissivity of water decreases with $\theta$ more than $7 \%$ from its nadir value [11]. Given the presence of OM content in those IBSs, which is the principal storage of plant available water due to the high percentage of water-stable aggregates, water content retained by these samples is usually greater than for sandy soils, so angular behavior of water emissivity probably influenced the decrease of $\varepsilon_{\mathrm{ri}}$ with $\theta$ for high SM contents at spectral ranges 8-9.4 $\mu \mathrm{m}, 10-12 \mu \mathrm{m}$ and broadband range 7.7-14.3 $\mu \mathrm{m}$. 
TABLE II

COEFFICIENTS $P_{0}-P_{4}$ OF POLYNOMIALS (3) AND (4) AT ALL SIX SPECTRAL CHANNELS. $\mathbf{R}^{2}$ AND RMSE ARE ALSO INCLUDED

\begin{tabular}{|c|c|c|c|c|c|c|c|c|c|c|c|c|}
\hline & a & b $\left(m^{3} m^{-3}\right)^{-1}$ & c & $d\left(m^{3} m^{-3}\right)$ & e $\left(m^{3} m^{-3}\right)^{-1}$ & f & $\mathbf{a}$ & b $\left(m^{3} m^{-3}\right)^{-1}$ & c & $d\left(m^{3} m^{-3}\right)^{-2}$ & e $\left(\mathrm{m}^{3} \mathrm{~m}^{-3}\right)^{-1}$ & f \\
\hline & \multicolumn{6}{|c|}{ CH 1: 7.7-14.3 $\mu \mathrm{m}$} & \multicolumn{6}{|c|}{ CH 4: 8.9-9.4 $\mu \mathrm{m}$} \\
\hline $\mathrm{P}_{0}$ & 0.998 & -0.003 & $16 \cdot 10^{-5}$ & -0.03 & 0.0006 & $-9 \cdot 10^{-6}$ & 1.001 & -0.04 & 0.0003 & 0.03 & 0.03 & $-1 \cdot 10^{-5}$ \\
\hline $\mathrm{p}_{1}$ & $2 \cdot 10^{-5}$ & -0.0002 & $-10 \cdot 10^{-5}$ & 0.0004 & -0.0006 & $4 \cdot 10^{-6}$ & $3 \cdot 10^{-5}$ & -0.0011 & $14 \cdot 10^{-8}$ & 0.0019 & 0.0019 & $-2 \cdot 10^{-7}$ \\
\hline $\mathrm{p}_{2}$ & -0.0007 & 0.003 & $6 \cdot 10^{-5}$ & -0.003 & $-6 \cdot 10^{-5}$ & $-7 \cdot 10^{-7}$ & -0.0008 & 0.005 & $4 \cdot 10^{-5}$ & -0.004 & $-13 \cdot 10^{-5}$ & $-2 \cdot 10^{-8}$ \\
\hline $\mathrm{p}_{3}$ & $-3 \cdot 10^{-6}$ & $3 \cdot 10^{-5}$ & $12 \cdot 10^{-7}$ & $-6 \cdot 10^{-5}$ & $17 \cdot 10^{-6}$ & $-7 \cdot 10^{-8}$ & $-410^{-6}$ & $6 \cdot 10^{-5}$ & $-17 \cdot 10^{-8}$ & $-10 \cdot 10^{-5}$ & $-5 \cdot 10^{-7}$ & $8 \cdot 10^{-9}$ \\
\hline $\mathrm{p}_{4}$ & $15 \cdot 10^{-5}$ & $-7 \cdot 10^{-5}$ & $-11 \cdot 10^{-7}$ & $9 \cdot 10^{-5}$ & $6 \cdot 10^{-7}$ & $16 \cdot 10^{-9}$ & $-16 \cdot 10^{-6}$ & $-9 \cdot 10^{-5}$ & $-8 \cdot 10^{-7}$ & $9.6 \cdot 10^{-5}$ & $2 \cdot 10^{-6}$ & $5 \cdot 10^{-10}$ \\
\hline $\mathrm{R}^{2}$ & 0.85 & 0.89 & 0.77 & 0.72 & 0.90 & 0.79 & 0.97 & 0.97 & 0.76 & 0.94 & 0.97 & 0.93 \\
\hline \multirow[t]{2}{*}{ RMSE } & 0.004 & 0.018 & 0.0003 & 0.04 & 0.0004 & $4 \cdot 10^{-6}$ & 0.002 & 0.018 & 0.0003 & 0.04 & 0.0004 & $4 \cdot 10^{-6}$ \\
\hline & \multicolumn{6}{|c|}{ CH 2: 10.9-11.9 $\mu \mathrm{m}$} & \multicolumn{6}{|c|}{ CH 5: 8.4-8.9 $\mu \mathrm{m}$} \\
\hline $\mathrm{P}_{0}$ & 0.998 & -0.008 & $13 \cdot 10^{-5}$ & 0.009 & $16 \cdot 10^{-5}$ & $-5 \cdot 10^{-6}$ & 0.996 & 0.010 & 0.0003 & -0.12 & 0.0016 & $-14 \cdot 10^{-6}$ \\
\hline $\mathrm{p}_{1}$ & 0.003 & 0.006 & $-11 \cdot 10^{-5}$ & -0.03 & -0.0003 & $13 \cdot 10^{-7}$ & $5 \cdot 10^{-5}$ & -0.0011 & $4 \cdot 10^{-7}$ & 0.002 & $1.2 \cdot 10^{-5}$ & $-16 \cdot 10^{-8}$ \\
\hline $\mathrm{p}_{2}$ & -0.0013 & 0.005 & $6 \cdot 10^{-5}$ & -0.004 & $-6 \cdot 10^{-5}$ & $-7 \cdot 10^{-7}$ & -0.0006 & 0.003 & $4 \cdot 10^{-5}$ & 0.0016 & $-17 \cdot 10^{-5}$ & $2 \cdot 10^{-7}$ \\
\hline $\mathrm{p}_{3}$ & $-5 \cdot 10^{-5}$ & -0.0003 & $12 \cdot 10^{-7}$ & 0.0011 & $11 \cdot 10^{-6}$ & $-11 \cdot 10^{-9}$ & $-4 \cdot 10^{-6}$ & $5 \cdot 10^{-5}$ & $-3 \cdot 10^{-7}$ & $-9 \cdot 10^{-5}$ & $17 \cdot 10^{-7}$ & $7 \cdot 10^{-9}$ \\
\hline $\mathrm{p}_{4}$ & $2 \cdot 10^{-5}$ & $-7 \cdot 10^{-5}$ & $-12 \cdot 10^{-7}$ & $4 \cdot 10^{-5}$ & $7 \cdot 10^{-7}$ & $13 \cdot 10^{-9}$ & $13 \cdot 10^{-6}$ & $-6 \cdot 10^{-5}$ & $-7 \cdot 10^{-7}$ & $3 \cdot 10^{-5}$ & $2 \cdot 10^{-6}$ & $-3 \cdot 10^{-9}$ \\
\hline $\mathrm{R}^{2}$ & 0.99 & 0.95 & 0.81 & 0.76 & 0.82 & 0.79 & 0.95 & 0.92 & 0.79 & 0.83 & 0.97 & 0.95 \\
\hline \multirow[t]{2}{*}{ RMSE } & 0.0011 & 0.012 & 0.0002 & 0.04 & 0.0004 & $3 \cdot 10^{-6}$ & 0.0019 & 0.02 & 0.0002 & 0.05 & 0.0004 & $4 \cdot 10^{-6}$ \\
\hline & \multicolumn{6}{|c|}{ CH 3: 10.1-11.1 $\mu \mathrm{m}$} & \multicolumn{6}{|c|}{ CH 6: 8.2-8.7 $\mu \mathrm{m}$} \\
\hline $\mathrm{P}_{0}$ & 0.999 & -0.017 & 0.00011 & 0.018 & 0.0003 & $-6 \cdot 10^{-6}$ & 0.992 & 0.066 & $8 \cdot 10^{-5}$ & -0.32 & 0.0024 & $-17 \cdot 10^{-6}$ \\
\hline $\mathrm{p}_{1}$ & 0.0012 & 0.015 & $-3 \cdot 10^{-5}$ & -0.04 & -0.0006 & $19 \cdot 10^{-7}$ & $9.5 \cdot 10^{-5}$ & -0.0017 & $3 \cdot 10^{-6}$ & 0.004 & $3 \cdot 10^{-6}$ & $-13 \cdot 10^{-8}$ \\
\hline $\mathrm{p}_{2}$ & -0.0012 & 0.005 & $6 \cdot 10^{-5}$ & -0.004 & $-6 \cdot 10^{-5}$ & $-7 \cdot 10^{-7}$ & -0.0003 & -0.0006 & $4 \cdot 10^{-5}$ & 0.011 & -0.0002 & $4 \cdot 10^{-7}$ \\
\hline $\mathrm{p}_{3}$ & $-6 \cdot 10^{-6}$ & -0.0005 & $-4 \cdot 10^{-7}$ & 0.0013 & $18 \cdot 10^{-6}$ & $-3 \cdot 10^{-8}$ & $-7 \cdot 10^{-6}$ & $8 \cdot 10^{-5}$ & $-4 \cdot 10^{-7}$ & -0.0002 & $6 \cdot 10^{-7}$ & $6 \cdot 10^{-9}$ \\
\hline $\mathrm{p}_{4}$ & $2 \cdot 10^{-5}$ & $-6 \cdot 10^{-5}$ & $-10 \cdot 10^{-7}$ & $3 \cdot 10^{-5}$ & $6 \cdot 10^{-7}$ & $14 \cdot 10^{-9}$ & $9 \cdot 10^{-6}$ & $-3 \cdot 10-5$ & $-6 \cdot 10^{-7}$ & $-4 \cdot 10^{-5}$ & $2 \cdot 10^{-6}$ & $-5 \cdot 10^{-9}$ \\
\hline $\mathrm{R}^{2}$ & 0.97 & 0.96 & 0.74 & 0.83 & 0.87 & 0.73 & 0.99 & 0.98 & 0.84 & 0.99 & 0.98 & 0.94 \\
\hline RMSE & 0.0017 & 0.011 & 0.0003 & 0.03 & 0.0004 & $4 \cdot 10^{-6}$ & 0.0003 & 0.012 & 0.0002 & 0.02 & 0.0004 & $4 \cdot 10^{-6}$ \\
\hline
\end{tabular}

\section{PARAmeterization of $\varepsilon_{r}(S M, \theta)$}

A parameterization of $\varepsilon_{\text {ri }}$ varying simultaneously with SM and $\theta$ was derived from all measurements. It was decided to split the number of IBS samples in two groups, first group was composed by seven samples (WS, B, F, LW45, C, D and BR1) representing full ranges of textural and mineralogical parameters, as well as OM. Rest IBS samples (BR3, LW03, BR2, LW13 and LW52) were used to validate the parameterization model obtained from first group.

The model that best fits the measurements is:

$\varepsilon_{r i}(S M, \theta)=a_{i}+b_{i} S M+c_{i} \theta+d_{i} S M^{2}+e_{i} S M \theta+f_{i} \theta^{2}$

where variance of coefficients $a_{i}-f_{i}$ in (2) were evaluated, using statistical factor analysis [12], for all data available in Table I following the procedure used in [6], full details can be found in that work.

The coefficients $a_{i}-f_{i}$ are dependent on clay and quartz content at the spectral range 8-9.4 $\mu \mathrm{m}$ (CE 312-2 channels 4, 5 and 6) by means of the equation:

$a-f_{8-9.4 \mu m}(C, Q)=p_{0}+p_{1} Q+p_{2} C+p_{3} C Q+p_{4} C^{2}$ where $p_{0}-p_{5}$ are coefficients of the polynomial given in equation (3), whose values can be found in Table II, C and Q are the percentages of clay and quartz, respectively.

Coefficients $a_{i}-f_{i}$ at spectral range 10-12 $\mu \mathrm{m}$ (CE312-2 channels 2 and 3 ) were found to be dependent on clay and OM content, following:

$a-f_{10-12 \mu m}(C, O M)=p_{0}+p_{1} O M+p_{2} C+p_{3} C O M+$
$p_{4} C^{2}$

For the broad range 7.7-14.3 $\mu \mathrm{m}$ (CE312-2 channel 1), coefficients $a, b$ and $d$ were dependent on clay and quartz contents, following equation (3), while coefficients $c$, $e$ and $f$ showed dependence on clay and OM, following Eq. (4). Table II summarizes values for coefficients $p_{0}-p_{5}$ of (3) and (4) at all six spectral ranges; statistics $\mathrm{R}^{2}$ and RMSE are also included.

Figure 3 shows the comparison between the observed $\varepsilon_{\mathrm{ri}}(\mathrm{SM}, \theta)$ values measured for the IBS samples BR3, LW03, BR2, LW13 and LW5 and those values modeled for the same samples using expressions (2), (3) and (4) at the three considered spectral ranges (see section III) Comparison was made for $\theta \geq 30^{\circ}$, since at this zenith angle are observed decreasing of $\varepsilon_{\text {ri }}$ from nadir greater than 0.01 . Results showed $\mathrm{R}^{2}$ ranging between 0.65 and 0.84 and RMSE ranges between \pm 0.005 and \pm 0.011 .
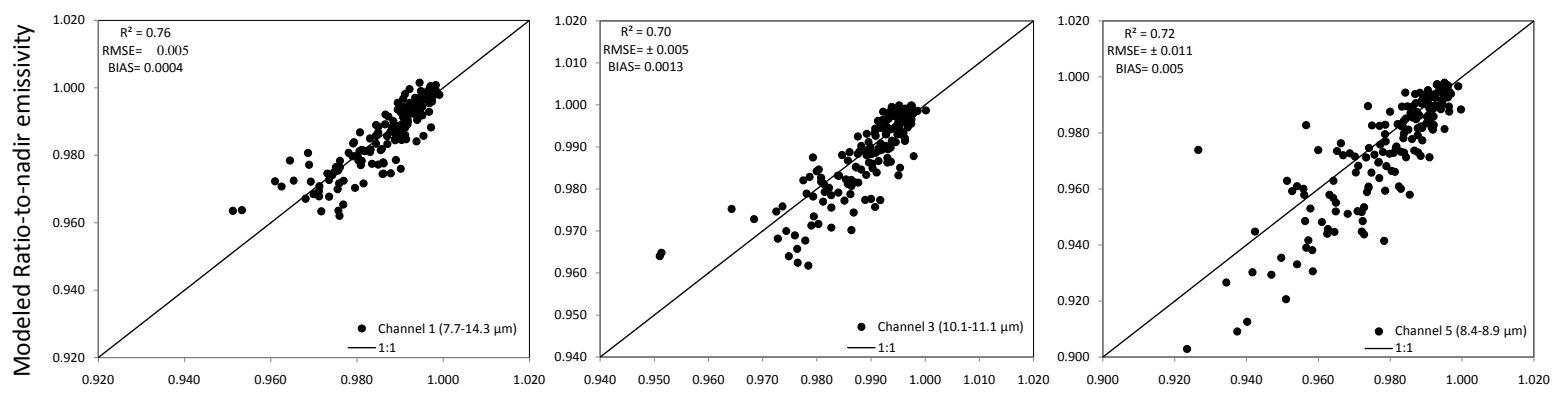

Observed Ratio-to-nadir emissivity

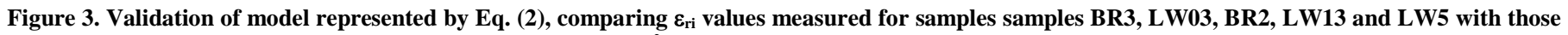

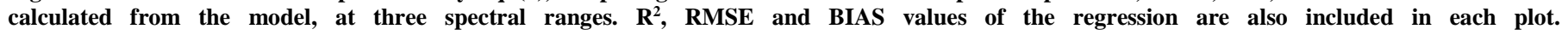


Estimation of clay, OM and quartz contents needed for equations (2)-(4) from remote sensing data was discussed in the works [3], [4], and [6], based on results of [13], [14] and [15]. Another possibility is the previous knowledge of clay, quartz and OM contents from ancillary data. In these cases the parameterizations given in expressions (2), (3) and (4), depending on spectral channel, could be applied to classification-based emissivity mapping, such as the one used in MODIS [16], SEVIRI [17], or more recently AATSR data [18], in order to refine their algorithms. In relation to the SM estimations for equation (2), they could be obtained from recent sensors such as the Microwave Imaging Radiometer by Aperture Synthesis (MIRAS) aboard the Soil Moisture and Ocean Salinity (SMOS) mission [19], or the Advanced Microwave Scanning Radiometer (AMSR-E) on board the EOS-Aqua platform [20], with spatial resolutions of $40 \mathrm{~km}$ (SMOS) and $56 \mathrm{~km}$ (AMSR-E), and expected accuracies of $\pm 0.04 \mathrm{~m}^{3} \cdot \mathrm{m}^{-3}$.conclusions

\section{CONCLUSIONS}

Angular effects of emissivity under controlled SM contents were assessed for a wide variety of IBS according their textural classification. Ratio-to-nadir emissivity values were retrieved taking two simultaneous radiance measurements, one at nadir and another one at an angular direction $(\theta, \varphi)$, with a maximum uncertainty of \pm 0.01 . Results showed that the effect of SM on $\varepsilon_{\mathrm{ri}}(\mathrm{SM}, \theta)$ exhibits three different behaviors as a function of the spectral range and textural composition of the sample. So, for sandy soils (B, BR3, WS and LW03) and the silty soil LW45, $\varepsilon_{\text {ri }}$ decreases significantly with $\theta$ under dry conditions reaching differences up to 0.132 (sample $\mathrm{B}, \theta=70^{\circ}$ ) from nadir values, but decreasing of $\varepsilon_{\mathrm{ri}}(\mathrm{SM}, \theta)$ with zenith angle is less notable when SM increases. It could be explained with the increase of water content in the soil, which results in a decrease of the spectral contrast of emissivity, because water is strongly absorbing in the region of the quartz retstrahlen bands. It is expected that water content interacts with gypsum (sample WS) similarly as quartz at reststrahlen bands. At spectral ranges 7.7-14.3 $\mu \mathrm{m}$ and 10-12 $\mu \mathrm{m}$, decrease of $\varepsilon_{\mathrm{ri}}(\mathrm{SM}, \theta)$ with zenith angle for sandy soils is significant for $\theta$ $\geq 50^{\circ}$; however it is independent on water content. Clayey IBS showed an almost constant fall of $\varepsilon_{\mathrm{r}}$ with $\theta$ at all spectral ranges studied, regardless the SM content, being the decreases of $\varepsilon_{\mathrm{r}}$ with $\theta$ significant for observation angles greater than $50^{\circ}$. Finally loamy IBS samples presented an opposite behavior to that of sandy soils, $\varepsilon_{\text {ri }}$ decreasing with $\theta$ more sharply with the increase of SM at all six spectral ranges studied and reaching differences from 0.011 for dry soils to 0.035 under saturated conditions.

In summary, the effect of $\mathrm{SM}$ on $\varepsilon_{\mathrm{ri}}(\mathrm{SM}, \theta)$ reduces its angular contrast under dry conditions up to 0.07 when sandy soil is saturated (because sandy soils are very poor water retainers) and counteracting the quartz and gypsum reststrahlen effects at 8-9.4 $\mu \mathrm{m}$. On the other hand, SM makes the decrease of $\varepsilon_{\mathrm{ri}}(\mathrm{SM}, \theta)$ with $\theta$ more noticeable for loamy soils (which are very good water retainers due the presence of $\mathrm{OM}$ ) because the decrease of water emissivity with observation angle, that may reach differences from its nadir value up to 0.04 at $\theta=70^{\circ}$.

Finally, a parameterization of $\varepsilon_{\mathrm{r}}$ with $\mathrm{SM}$ and $\theta$ was obtained allowing to obtain $\varepsilon_{\mathrm{r}}$ with a maximum accuracy of \pm 0.011 , by means of a quadratic-polynomial whose coefficients are dependent on percentages of clay and quartz and OM content at spectral range 8-9.4 $\mu \mathrm{m}, 10-12 \mu \mathrm{m}$ and 7.7-14.3 $\mu \mathrm{m}$.

\section{REFERENCES}

[1] J. M Sánchez, V. Caselles, R. Niclos, C. Coll and W.P. Kustas, "Estimating energy balance fluxes above a boreal forest from radiometric temperature observations”, Agr. Forest Meteorol., vol. 149, no. 67, pp. 1037-1049, 2009, doi: 10.1016/j.agrformet.2008.12.009.

[2] J. W. Salisbury and D. M. D’Aria, "Infrared (8-14 $\mathrm{mm}$ ) remote sensing of soil particle size”, Remote Sens. Environ., vol. 42, pp. 157-165, 1992.

[3] M. Mira, E. Valor R. Boluda, V. Caselles, and C. Coll, "Influence of soil water content on the thermal infrared emissivity of bare soils: Implication for land surface temperature determination”, J. Geophys. Res., vol. 112, F04003, 2007, doi:10.1029/2007JF000749.

[4] M. Mira, E. Valor, V. Caselles, E. Rubio, C. Coll, J. M. Galve, R. Niclos, J.M. Sánchez, and R. Boluda, "Soil Moisture Effect on Thermal Infrared (8-13- $\mu \mathrm{m})$ Emissivity”, IEEE Trans. Geosci. Remote Sens., vol. 48, no. 5, pp. 2251-2260, 2010, doi:10.1109/TGRS.2009.2039143.

[5] J. Labed and M. P. Stoll (1991), “Angular variation of land surface spectral emissivity in the thermal infrared: laboratory investigations on bare soils”. Int. J. Remote Sens., vol. 12, pp. 2299-2310, doi:10.1080/01431169108955259.

[6] V. García-Santos, E. Valor, V. Caselles, M.A. Burgos and C. Coll, "On the angular variation of thermal infrared emissivity of inorganic soils”, J. Geophys. Res., $\quad$ vol. $117 \quad$ (D19116), 2012, doi:10.1029/2012JD017931.

[7] G. Brogniez, C. Pietras, M. Legrand, P. Dubuisson, and M. Haeffelin, “A high-accuracy multiwavelength radiometer for in situ measurements in the thermal infrared. Part II: Behavior in field experiments", J. Atmos. Ocean Technol., vol. 20, no. 7, pp. 10231033, 2003.

[8] E. Theocharous, and N. P. Fox, "CEOS comparison of IR brightness temperature measurements in support of satellite validation. Part II: Laboratory comparison of the brightness temperature of blackbodies”, NPL REPORT OP4, Teddington, UK: National Physical Laboratory, ISSN: 1754-2944, 2010.

[9] V. García-Santos, E. Valor, V. Caselles, M. Mira, J. M. Galve and C. Coll, "Evaluation of different methods to retrieve the hemispherical downwelling irradiance in the thermal infrared region for field 
measurements”, IEEE Trans. Geosci. Remote Sens., vol. 51, no. 4, pp. 2155-2165, 2012, doi:10.1109/TGRS.2012.2209891.

[10] A. Field, Discovering Statistics Using SPSS, 3rd edition, 2455 Teller Road Thousand Oaks, CA 91320, SAGE Publications Ltd, 2009

[11] A.M. Baldridge, S.J. Hook, C.I. Grove and G. Rivera, The ASTER spectral library version 2.0, vol. 113, pp. 711-715, 2009, doi:10.1016/j.rse.2008.11.007.

[12] R. Niclòs, E. Valor, V. Caselles, C. Coll, and J. M. Sánchez, "In situ angular measurements of thermal infrared sea surface emissivity-Validation of models”, Remote Sens. Environ., vol. 94, no. 1, pp. 83-93, 2005, doi: 10.1016/j.rse.2004.09.002.

[13] D. Singh and A. Kathpalia, "An efficient modeling with GA approach to retrieve soil texture, moisture and roughness from ERS-2 SAR data”, Progress In Electromagnetics Research, vol. 77, pp. 121-136, 2007. doi:10.2528/PIER07071803.

[14] Y. Ninomiya and B. Fu, "Spectral indices for lithologic mapping with ASTER thermal infrared data applying to a part of Beishan Mountains, Gansu, China," in Proc. IEEE Int. Geosci. Remote Sens. Symp., vol. 7, pp. 2988-2990, 2001.

[15] C. Wu, J. Wu, Y. Luo, L. Zhang, and S. D. DeGloria, "Spatial prediction of soil organic matter content using cokriging with remotely sensed data," Soil Sci. Soc. Amer. J., vol. 73, vol. 4, pp. 1202-1208, 2009.

[16] W.C. Snyder, Wan, Z., Zhang, Y., and Feng, Y.Z., "Classification-based emissivity for land surface temperature measurement from space”, Int. J. Remote Sens. vol. 19, pp. 2753-2774, 1998.

[17] I.F. Trigo, Peres, L.F., DaCamara, C.C. and Freitas, S.C., "Thermal land surface emissivity retrieved from SEVIRI/Meteosat”. IEEE Trans. Geosci. Remote Sens., vol. 46, pp. 307-315, 2008.

[18] E. Caselles, E. Valor, F.J. Abad and V. Caselles, "Automatic classification-based generation of thermal infrared land surface emissivity maps using AATSR data over Europe", Remote Sens. Environ., vol. 124, pp. 321-333, 2012, doi: 10.1016/j.rse.2012.05.024.

[19] Y. H. Kerr, P. Waldteufel, J. P. Wigneron, J. M. Martinuzzi, J. Font, andM. Berger, "Soil moisture retrieval from space: The Soil Moisture and Ocean Salinity (SMOS) mission,” IEEE Trans. Geosci. Remote Sens., vol. 39, no. 8, pp. 1729-1735, Aug. 2001.

[20] T. Kawanishi, T. Sezai, Y. Ito, K. Imaoka, T. Takeshima, Y. Ishido,A. Shibata, M. Miura, H. Inahata, and R. W. Spencer, "The Advanced Microwave Scanning Radiometer for the Earth Observing System (AMSRE), NASDA's contribution to the EOS for global energy and water cycle studies,” IEEE Trans. Geosci. Remote Sens., vol. 41, no. 2, pp. 184-194, Feb. 2003. 